\title{
Tachykinin Signaling Is Required for Induction of the Preovulatory Luteinizing Hormone Surge and Normal Luteinizing Hormone Pulses
}

\author{
Silvia León ${ }^{a, b} \quad$ Chrysanthi Fergani ${ }^{a, b} \quad$ Rajae Talbia,b Caroline A. Maguire ${ }^{b}$ \\ Achi Gerutshang $^{b}$ Stephanie B. Seminara ${ }^{a, c}$ Victor M. Navarro ${ }^{a, b}, d$ \\ ${ }^{a}$ Harvard Medical School, Boston, MA, USA; ${ }^{b}$ Division of Endocrinology, Diabetes and Hypertension, \\ Department of Medicine, Brigham and Women's Hospital, Boston, MA, USA; ' Harvard Reproductive Sciences Center \\ and Reproductive Endocrine Unit, Department of Medicine, Massachusetts General Hospital, Boston, MA, USA; \\ ${ }^{\mathrm{d}}$ Harvard Program in Neuroscience, Boston, MA, USA
}

\section{Keywords}

Tachykinin signaling · Preovulatory luteinizing hormone surge $\cdot$ Luteinizing hormone pulses

\begin{abstract}
Tachykinins (neurokinin A [NKA], neurokinin B [NKB], and substance $P[S P]$ ) are important components of the neuroendocrine control of reproduction by direct stimulation of Kiss 1 neurons to control GnRH pulsatility, which is essential for reproduction. Despite this role of tachykinins in successful reproduction, knockout (KO) mice for Tac1 (NKA/SP) and Tac2 (NKB) genes are fertile, resembling the phenotype of human patients bearing NKB signaling mutations, who often reverse their hypogonadal phenotype. This suggests the existence of compensatory mechanisms among the different tachykinin ligand-receptor systems to maintain reproduction in the absence of one of them. In order to test this hypothesis, we generated complete tachykinin-deficient mice (Tac1/Tac2KO). Male mice displayed delayed puberty onset and decreased luteinizing hormone (LH) pulsatility (frequency and amplitude of LH pulses) but preserved fertility. However, females did not show signs of puberty onset (first es-
\end{abstract}

karger@karger.com www.karger.com/nen

Karger $\stackrel{2}{\circ}$ trus) within 45 days after vaginal opening, they displayed a low frequency (but normal amplitude) of LH pulses, and $80 \%$ of them remained infertile. Further evaluation identified a complete absence of the preovulatory LH surge in Tac1/ Tac2KO females as well as in wild-type females treated with NKB or SP receptor antagonists. These data confirmed a fundamental role of tachykinins in the timing of puberty onset and LH pulsatility and uncovered a role of tachykinin signaling in facilitation of the preovulatory LH surge. Overall, these findings indicate that tachykinin signaling plays a dominant role in the control of ovulation, with potential implications as a pathogenic mechanism and a therapeutic target to improve reproductive outcomes in women with ovulation impairments.

(c) 2020 S. Karger AG, Basel

\section{Introduction}

Tachykinins are a family of peptides comprised of neurokinin $\mathrm{A}(\mathrm{NKA})$ and substance $\mathrm{P}(\mathrm{SP})$, encoded by Tac1, and neurokinin $\mathrm{B}(\mathrm{NKB})$, encoded by Tac2 (TAC3 in humans) [1]. Inactivating mutations in the TAC3 gene and 
in the gene encoding the NKB receptor NK3R (TACR3) lead to hypogonadotropic hypogonadism $(\mathrm{HH})$ and infertility in human patients $[2,3]$. NKB is expressed in Kiss1 neurons of the arcuate nucleus (ARC) (Kiss1 ${ }^{\mathrm{ARC}}$ ), which express kisspeptin, the most potent secretagogue of GnRH identified to date $[4,5]$. Our lab and others have contributed to an extensive body of literature that supports a predominantly stimulatory role of $\mathrm{NKB}$ on the reproductive axis, acting as a regulator of kisspeptin release to stimulate $\mathrm{GnRH}$ pulses [1]. This role is supported by the infertile phenotype of human patients bearing TAC3/TACR3 mutations. Because Tac1 is not expressed in Kiss1 neurons but rather upstream of these [6], and despite the documented stimulatory effect of SP [6-13] and NKA $[6,14,15]$ on LH release no inactivating mutations in this gene have been reported as causative of $\mathrm{HH}$ in humans to date. This indicates that the absence of NKA/SP signaling can be compensated for by alternative neurocircuitries and/or that their role is merely to fine tune kisspeptin release. Interestingly, despite this critical role of $\mathrm{NKB}$, a number of $\mathrm{NKB}$ signaling-deficient patients reverse their hypogonadal phenotype [16], being able to have successful pregnancies before relapsing into their $\mathrm{HH}$ state again. This suggests that, under specific circumstances, NKB signaling can be compensated for, leading to temporary activation of the reproductive axis. In fact, this phenotype is in line with that observed in mouse models devoid of NKB signaling (Tac2KO and Tacr3KO) $[17,18]$ and NKA/SP signaling (Tac1KO) [11, 19]. These mouse models present a delayed puberty onset but overall preserved fertility. Importantly, although SP and NKB have a high affinity for NK1R and NK3R receptors, respectively; NKB can also bind NK1R and, similarly, SP can activate NK3R, suggesting a high degree of redundancy in the tachykinin system with strong a likelihood of compensation in the absence of one of the ligand/ receptor systems $[20,21]$. We hypothesized that this degree of redundancy is the answer to the reversal of the $\mathrm{HH}$ phenotype observed in NKB/NK3R-null patients, as well as the reason for the preserved fertility in each of the individual KO mouse models. In order to assess this hypothesis, we generated a complete tachykinin-null mouse model (Tac1/Tac2 KO) and complete reproductive characterization was performed in both sexes.

\section{Materials and Methods}

Mice. Tac2 KO (knockout; KO) mice were obtained from Dr. Seminara (Massachusetts General Hospital) [17]. Tac1/Tac2 KO were generated by crossing Tac1KO (stock No. 004103; The Jack- son Laboratory) and Tac2KO mice. Mice were maintained in a 12:12 h light/dark cycle and fed a standard rodent chow diet and water ad libitum. Genotyping was conducted by PCR analyses on isolated genomic DNA from tail biopsies.

Reagents. The antagonists of NK3R (SB 222200) and NK1R (RP67580) were purchased from Tocris Bioscience (Minneapolis, MN, USA). The doses and timings for hormonal analyses were selected on the basis of previous studies $[6,22,23]$.

\section{Experimental Design}

Study 1: Reproductive Maturation of Tac1/Tac2 KO Male and Female Mice.

In order to assess the reproductive phenotype of mice lacking all of the tachykinins, and therefore prevent cross reactivity of their ligand-receptor systems that potentially compensates for the absence of one of them, we generated a double Tac1 and Tac2 KO mouse (Tac1/Tac2KO). Prepubertal littermate wild-type (WT) $(n=11)$ and Tac1/Tac2 KO $(n=14)$ males were monitored daily from postnatal day 25 for preputial separation as an indirect marker of puberty onset. Body weight (BW) was measured at the average age of puberty onset (day 28$)$.

In females, littermate WT $(n=12)$ and Tac1/Tac2 KO $(n=8)$ mice were monitored daily from postnatal day 25 for BW and pubertal progression (vaginal opening [VO] as indicated by complete canalization of the vagina) and first estrus (first day with cornified cells determined by daily [morning] vaginal cytology) during 45 days after the day of VO. In addition, estrous cyclicity was monitored by daily vaginal cytology, for a period of 30 days, in young (3 months old) and older ( 8 months old) WT and Tac1/Tac2 KO $(n \geq 8)$ mice. Cytology samples were obtained every morning (10:00 a.m.) and placed on a glass slide for determination of the estrous cycle under the microscope as previously described [24].

Study 2: Fecundity Test in Tac1/Tac2 KO Male and Female Mice.

In this study, adult WT $(n=3)$ or Tac1/Tac2 KO $(n=7)$ male littermate mice ( $>75$ days) were placed with proven fertile WT females and the time to delivery and the number of pups per litter were monitored. In females, the fertility assessment was performed by breeding adult WT $(n=3)$ or Tac1/Tac2 KO $(n=10)$ females with WT males previously proven to father litters. The time to the first litter and the number of pups per litter were recorded.

Additionally, the testes' ultrastructure was analyzed in adult (3-4 months old) mice of the 2 genotypes, i.e., WT and Tac1/Tac2 KO ( $n=4$ /group). Testes were collected, weighed, and fixed in Bouin's solution. The tissues were embedded in paraffin and sectioned $(10 \mu \mathrm{m})$ for hematoxylin and eosin staining (Harvard Medical School Rodent Pathology Core) and images were acquired under $\times 4$ magnification. In females, the ovarian ultrastructure was also analyzed in adult (3-4 months old) mice of the 2 genotypes, i.e., WT and Tac1/Tac2 KO ( $n=4$ /group). Ovaries were collected and processed as described above for the testes. The ovaries were analyzed for presence of corpora lutea (CL) per section. Each value represents the number of CL of 1 representative section from the middle line of one ovary per animal.

Study 3: Characterization of the Postgonadectomy Response of LH in Male and Female Mice.

Bilateral removal of testes from 3- to 4-month-old males was performed with light isoflurane anesthesia. Briefly, the ventral skin was shaved and cleaned to perform one small incision in the skin and abdominal musculature. Once the gonads had been identified and excised, the muscle incision was sutured and the skin was 
Table 1. Primers used

\begin{tabular}{lll}
\hline $\begin{array}{l}\text { Gene } \\
\text { name }\end{array}$ & Primer sequence & $\begin{array}{l}\text { Gene } \\
\text { accession No. }\end{array}$ \\
\hline Hprt & $\begin{array}{l}\text { F: CCTGCTGGATTACATTAAAGCGCTG } \\
\text { R: GTCAAGGGCATATCCAACAACAAAC }\end{array}$ & NM_013556.2 \\
\hline Tacr1 & $\begin{array}{l}\text { F: GTCTGCCAAGAGCCAAGAAC } \\
\text { R: CCAGCCACATCTGAGAGACA }\end{array}$ & NM_009313 \\
\hline Tacr2 & $\begin{array}{l}\text { F: TCAACTTCATCTATGCCAGTCAC } \\
\text { R: ATGACAGCAATAACCGCCTTG }\end{array}$ & NM_009314 \\
\hline Tacr3 & $\begin{array}{l}\text { F: GCCATTGCAGTGGACAGGTAT } \\
\text { Riss1 }\end{array}$ & $\begin{array}{l}\text { F: CTCTGTGGTCGGGCATGACTTTTA } \\
\text { R: TTCCCAGGCATTAACGAGTTC }\end{array}$ \\
\hline Pdyn & $\begin{array}{l}\text { F: ACAGGGGGAGACTCTCATCT } \\
\text { R: GGGGATGAATGACCTGCTTACT }\end{array}$ & AF472576.1 \\
\hline
\end{tabular}

F, forward; R, reverse.

closed with surgical clips. LH levels were measured in WT $(n=13)$ and Tac1/Tac2 KO $(n=10)$ mice. Blood samples were collected before and then 2 and 7 days after bilateral gonadectomy (GNX). Adult female mice were subjected to bilateral ovariectomy (OVX) via an abdominal incision under light isofluorane anesthesia and LH levels were measured in intact (diestrus in the morning) WT $(n=9)$ and Tac1/Tac2 KO $(n=6)$ adult (3-4 months) females and compared with values 2 and 7 days after OVX.

Study 4: Characterization of the LH Pulsatile Secretion in Males and Females.

We assessed the pulsatile secretion of LH in adult GNX male (4 weeks after GNX) Tac1/Tac2 KO mice and WT littermates $(n=$ 3-4 per group). Mice were handled daily to allow acclimation to the sampling conditions for 3 weeks prior to the experiment. Pulsatile measurements of $\mathrm{LH}$ secretion were assessed by repeated blood collection through a single excision at the tip of the tail, as described previously [25]. The tail was cleaned with saline and then massaged to take a $4-\mu \mathrm{L}$ blood sample with a pipette. Whole blood was immediately diluted in $116 \mu \mathrm{L}$ of $0.05 \%$ PBST, vortexed, and frozen on dry ice. Samples were stored at $-80^{\circ} \mathrm{C}$ for a subsequent LH ELISA. We collected sequential blood samples every $10 \mathrm{~min}$ over a 150 -min sampling period. Also, we assessed the pulsatile secretion of LH in adult OVX female (4 weeks after OVX) Tac1/ Tac2 KO mice and WT littermates ( $n=6-7$ per group), following the protocol described above for males.

Study 5: Expression of Tacr1, Tacr2, Tacr3, Kiss1, and Pdyn in the Mediobasal Hypothalamus of Female Mice.

We aimed to determine whether there are changes in the expression of Tacr1, Tacr2, Tacr3, Kiss1, and Pdyn in the mediobasal hypothalamus $(\mathrm{MBH})$, the site that includes the ARC, between WT and Tac1/Tac2 KO-intact females. The hypothalami were dissected taking as limits the posterior margin of the optic chiasm (rostrally) and the anterior margin of the mammillary bodies (caudally), with a dissection depth of approximately $2 \mathrm{~mm}$. Each hypothalamic sample was dissected and divided into 2 parts, i.e., the suprachiasmatic region (preoptic area; $\mathrm{POA}$ ) or the $\mathrm{MBH}$, and fragments were stored at $-80^{\circ} \mathrm{C}$ until further processing.
Total RNA from the MBH was isolated using TRIzol reagent (Invitrogen) followed by chloroform/isopropanol extraction. RNA was quantified using a NanoDrop 2000 spectrophotometer (Thermo Scientific), and $1 \mu \mathrm{m}$ of RNA was reverse transcribed using an iScript cDNA synthesis kit (Bio-Rad). Quantitative realtime PCR assays were performed on an ABI Prism 7000 sequence detection system and analyzed using ABI Prism 7000 SDS software (Applied Biosystems). The cycling conditions were the following: 2 min incubation at $95^{\circ} \mathrm{C}$ (hot start), 45 amplification cycles $\left(95^{\circ} \mathrm{C}\right.$ for $30 \mathrm{~s}, 60^{\circ} \mathrm{C}$ for $30 \mathrm{~s}$, and $45 \mathrm{~s}$ at $75^{\circ} \mathrm{C}$, with fluorescence detection at the end of each cycle), followed by a melting curve of the amplified products obtained by a ramped increase in temperature from 55 to $95^{\circ} \mathrm{C}$ to confirm the presence of a single amplification product per reaction. For data analysis, relative standard curves were constructed from serial dilutions of one reference sample cDNA and the input value of the target gene was standardized to Hprt levels in each sample. The primers used are listed in Table 1.

Study 6: Characterization of the Estradiol-Induced LH Surge.

In this study, WT $(n=5)$, Tac1 $\mathrm{KO}(n=5)$, Tac2 $\mathrm{KO}(n=5)$, and Tac1/Tac2 KO $(n=5)$ adult female mice were subjected to a bilateral OVX via an abdominal incision under light isofluorane anesthesia. Immediately after the OVX, capsules filled with $\mathrm{E}_{2}$ (1 $\mu \mathrm{g} / 20 \mathrm{~g}$ of body weight) were implanted subcutaneously via a small midscapular incision at the base of the neck; 5 days later, mice were subcutaneously injected in the morning with estradiol benzoate ( 1 $\mu \mathrm{g} / 20 \mathrm{~g}$ of body weight) to produce elevated proestrus-like $\mathrm{E}_{2}$ levels (LH surge) on the following day. Blood samples were collected at 10:00 a.m. and 7:00-17:30 p.m. [26]; LH levels were measured via ELISA.

Study 7: Effect of NK1R and NK3R Antagonists in the EstradiolInduced LH Surge in Female Mice.

In this study, we aimed to evaluate whether SP and NKB signaling are required to induce the preovulatory LH surge in WT females ( $n=5$ /group). An NK1R antagonist ( $5 \mathrm{mg} / \mathrm{kg})$, an NK3R antagonist $(5 \mathrm{mg} / \mathrm{kg})$, or vehicle (5\% DMSO) was administered during the morning (10:00 a.m.) and afternoon (5:00 p.m.) on the 

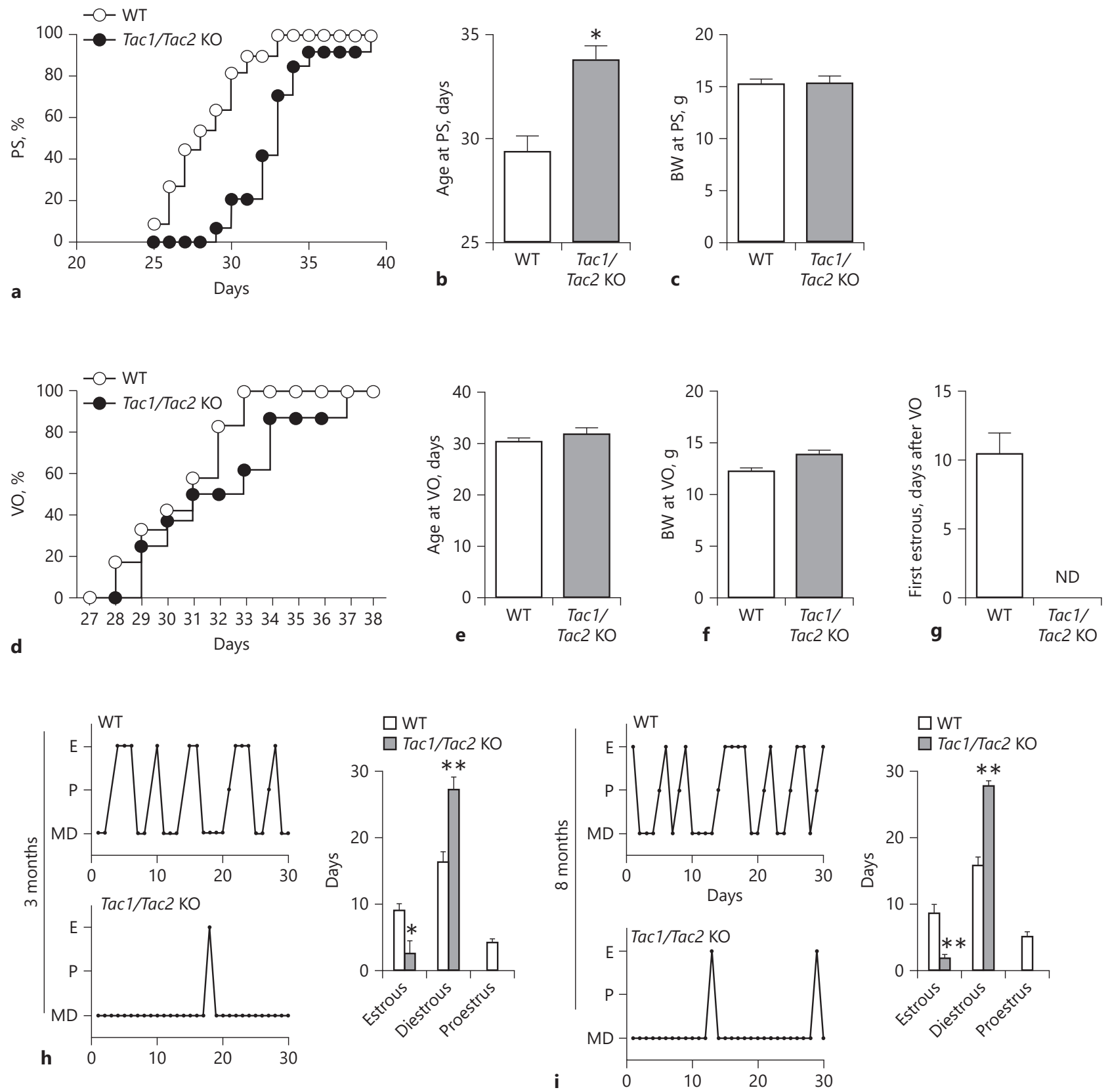

Fig. 1. Pubertal progression in male and female Tac1/Tac2KO mice. a, b Pubertal progression in males documented by preputial separation (PS) and body weight at the time of PS (c; $n \geq 11$ /group). d, e Pubertal progression in females documented by VO, body weight at VO (f) and first estrus ( $\mathbf{g} ; n \geq 8$ /group). Estrous cyclicity during 30 days at age 3 months (h) and 8 months (i; $n \geq 8$ /group). ${ }^{*} p<0.05$. ${ }^{* *} p<0.01$. Student $t$ test and oneway ANOVA followed by a Newman-Keuls post hoc test $(\mathbf{h}, \mathbf{i})$. 
day of the LH surge. The LH surge was induced following the protocol described above. Blood samples were collected at 10:00 a.m. (before the first injection of the antagonist) and at 7:00-7:30 p.m. and LH levels were measured via ELISA.

\section{Hormone Measurements}

LH was measured by a sensitive sandwich ELISA for assessment of whole blood LH concentrations as previously described elsewhere [25]. A 96-well high-affinity binding microplate (9018; Corning) was coated with $50 \mu \mathrm{L}$ of capture antibody (monoclonal antibody, anti-bovine LH $\beta$ subunit, 518B7; University of California) at a final dilution of 1:1,000 (in $1 \times \mathrm{PBS}, 1.09 \mathrm{~g}$ of $\mathrm{Na}_{2} \mathrm{HPO}_{4}$ [anhydrous], $0.32 \mathrm{~g}$ of $\mathrm{NaH}_{2} \mathrm{PO}_{4}$ [anhydrous], and $9 \mathrm{~g}$ of $\mathrm{NaCl}$ in $1,000 \mathrm{~mL}$ of distilled water) and incubated overnight at $4^{\circ} \mathrm{C}$. To minimize unspecific binding of the capture antibody, wells were incubated with $200 \mu \mathrm{L}$ of blocking buffer (5\% [weight/volume] skim milk powder in $1 \times$ PBS-T ( $1 \times$ PBS with $0.05 \%$ Tween 20$)$ for $2 \mathrm{~h}$ at room temperature. A standard curve was generated using a 2 -fold serial dilution of LH (reference preparation, AFP5306A; National Institute of Diabetes and Digestive and Kidney Diseases National Hormone and Pituitary Program [NIDDKNHPP]) in $0.2 \%$ (weight/volume) BSA- $1 \times$ PBS-T. The LH standards and blood samples were incubated with $50 \mu \mathrm{L}$ of detection antibody (polyclonal antibody, rabbit LH antiserum, and AFP240580Rb; NIDDK-NHPP) at a final dilution of 1:10,000 for $1.5 \mathrm{~h}$ (at room temperature). Each well containing bound substrate was incubated with $50 \mu$ of horseradish peroxidase conjugated antibody (poly-clonalgoatanti-rabbit, D048701-2; DakoCytomation) at a final dilution of 1:2,000. After a 1.5-h incubation, $100 \mathrm{UL}$ of o-phenylenediamine (002003; Invitrogen) substrate containing $0.1 \% \mathrm{H}_{2} \mathrm{O}_{2}$ was added to each well and left at room temperature for $30 \mathrm{~min}$. The reaction was stopped by addition of $50 \mu \mathrm{L}$ of $3 \mathrm{M} \mathrm{HCl}$ to each well, and the absorbance of each well was read at a wave length of $490 \mathrm{~nm}$ (Sunrise; Tecan Group). The concentration of LH in whole blood samples was determined by interpolating the optical density values of unknowns against a nonlinear regression of the LH standard curve [25]. The reported intra- and interassay coefficients of variation for this assay are 6.05 and $4.29 \%$, respectively [25].

\section{Statistical Analysis}

All data are expressed as the mean \pm SEM for each group. A 2-tailed unpaired Student $t$ test or a one- or two-way ANOVA test followed by a Newman-Kleus or repeated measures Fisher post hoc test was used to assess variation among experimental groups. $p<0.05$ was considered statistically significant. All analyses were performed with GraphPad Prism Software, Inc. (San Diego, CA, USA).

\section{Statistical Analysis of LH Pulses}

Mouse LH concentration time series were analyzed using a custom-made MATLAB-bases algorithm. It is a for loop written in the code to determine which $\mathrm{LH}$ peaks are considered pulses. This for loop states that any value whose height is $20 \%$ greater than the heights of the 2 previous values as well as $10 \%$ greater than the height of the following value is considered a pulse. There is also a condition written into the code that is specific for the second time interval $(i=2)$ that states that the value at the second time interval only needs to be $20 \%$ greater than the single value that comes before it to be considered a pulse.

\section{Results}

\section{Absence of Tachykinin Signaling Delays Puberty} Onset in Males and Females

As expected, Tac1/Tac2KO mice showed a delayed puberty onset in males (assessed by the age of preputial separation; Fig. 1a, b) despite a normal BW (Fig 1c). Interestingly, although Tac1/Tac2KO female mice had a normal timing of VO, there was no evidence of first estrus (marker for central activation of the reproductive axis) during the time of this study (45 days after VO), despite a BW similar to those of controls (Fig. 1d-g). Next, in order to better assess the fitness of the reproductive axis in females, estrous cyclicity was monitored for 30 days at 3 months of age ( 3 months) and 8 months. These ages were selected based on previous studies in Tac2KO females, which showed absent or irregular estrous cycles during the early adult phase ( 3 months) that progressed into regular cycles by the age of 8 months [17]. Tac1/Tac2KO female mice, however, presented disrupted estrous cycles at both ages, spending most of their time in diestrus with some few sporadic estrous phases over a 30-day period (Fig. 1h, i).

\section{Tachykinin Signaling Is Necessary for Normal Fertility} in Females but Not Males

In order to determine whether the delay in sexual maturation observed in peripubertal Tac1/Tac2KO male and female mice affects fertility, as suggested by the impaired estrous cycles (Fig. 1), Tac1/Tac2KO mice (both sexes) were subjected to a fecundity test. KO mice were housed with proven fertile WT mates for 2.5 months. As a result, $100 \%$ of the males fathered litters that were normal in size (Fig. 2a). The latency to impregnate females was also similar between groups (Fig. 2b). In addition, males displayed normal testicular weight and histology with the presence of mature sperm (Fig. 2c, d). Furthermore, in order to test the response of central elements of the HPG axis to the absence of negative feedback, males were castrated and LH samples collected before surgery (basal) and 2 and 7 days postsurgery. Interestingly, the compensatory rise of $\mathrm{LH}$ was present in WT but not in KO mice 2 days postcastration; however, the $\mathrm{LH}$ level in $\mathrm{KO}$ mice reached the level of the control group by 7 days (Fig. 2e).

On the other hand, the majority $(80 \%)$ of the female $\mathrm{KO}$ mice were infertile. In the remaining $20 \%$ of the females that got pregnant, the litter size was significantly smaller and the pregnancy latency significantly longer than in the controls (Fig. 2f-h). This was accompanied by a smaller ovarian size and significantly fewer CL, suggest- 


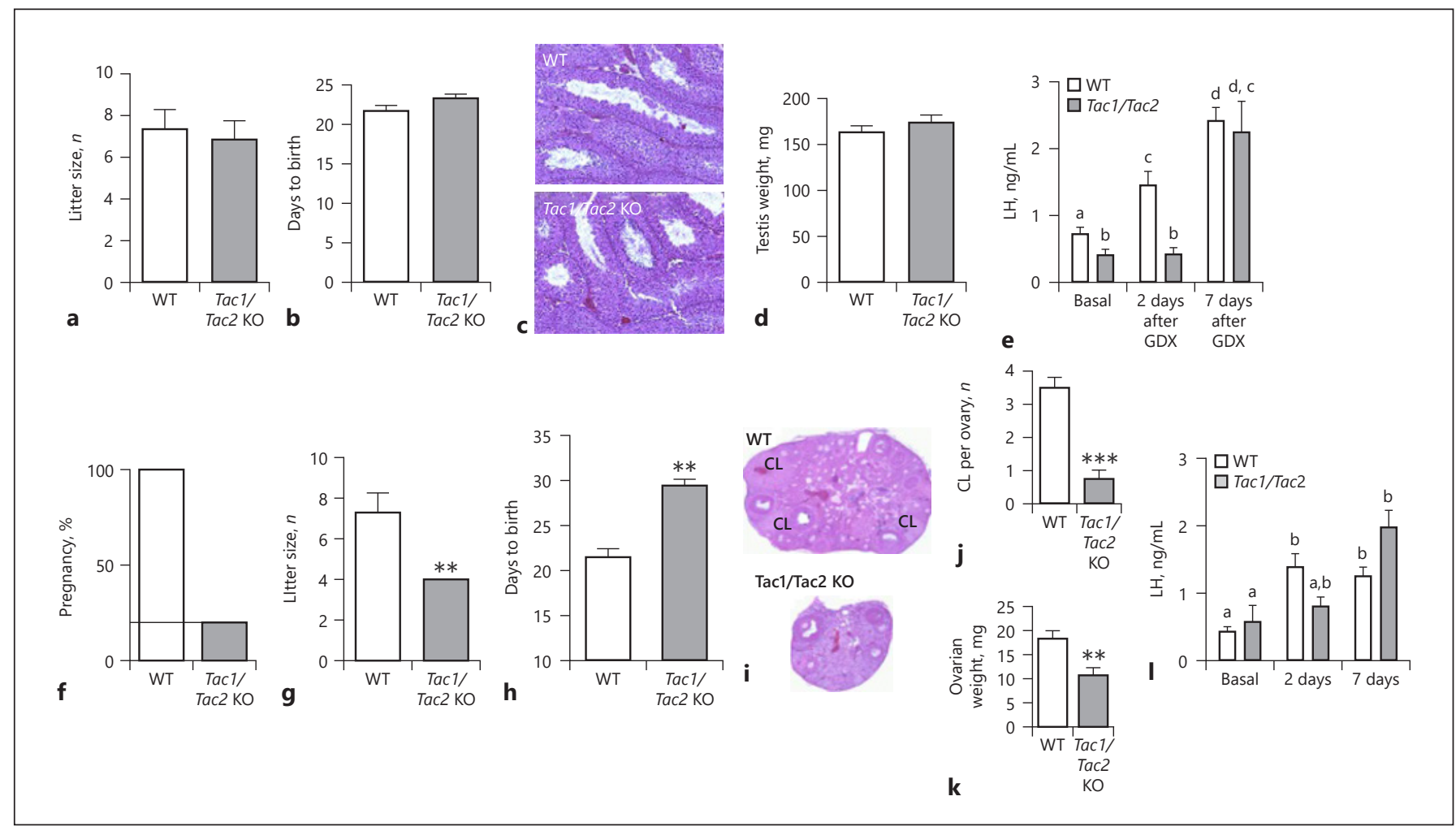

Fig. 2. Fecundity test, gonadal histology, and response to GNX in male and female Tac1/Tac2KO mice. Litter size (a), parturition latency (b), testicular histology (c), and testicular weights (d) in WT and Tac1/Tac2KO males ( $n=7$ /group). Circulating LH levels before (basal) and 2 and 7 days after castration (e; $n=10$ /group). In females, the percentage of fertile females during 11 weeks of mating (f), litter size (g), parturition latency (h), ovarian histology (i), the number of CL (j), and ovarian weights (k) in WT vs. Tac1/ Tac2KO females ( $n=10$ /group) are shown. Circulating LH levels before (basal) and 2 and 7 days after OVX (I). ${ }^{* *} p<0.01$. ${ }^{* * *} p<$ 0.001 . Student $t$ test. Different letters indicate significantly different values after a two-way ANOVA and a repeated measures Fisher post hoc test. ing an ovulation impairment (Fig. 2i-k) despite a slightly higher BW than controls (i.e., $21.75 \pm 1.06$ vs. $25.0 \mathrm{~g} \pm$ 0.76 for Tac1/Tac2KO; $p<0.05)$. However, at least $1 \mathrm{CL}$ could be found in $75 \%$ of the ovaries assessed in Tac1/ Tac2KO females. As in males, the response to the removal of the negative feedback after OVX was lower 2 days after surgery; however, in these females, the LH level did not reach statistical significance compared to controls 2 days postsurgery. Nonetheless, LH levels did not increase from baseline to 2 days after OVX, resembling the effect in male $\mathrm{KO}$ mice, while a significant $\mathrm{LH}$ rise 2 days after surgery was already detected in control animals. LH levels in $\mathrm{KO}$ mice recovered to control levels by 7 days (Fig. 2l).

\section{Absence of Tachykinin Signaling Decreases the}

Frequency and Amplitude of LH Pulses

The pattern of pulsatile LH release was assessed every $10 \mathrm{~min}$ for $150 \mathrm{~min}$ in $\mathrm{WT}$ and Tac1/Tac2KO mice of both sexes in a model of elevated LH pulsatility, i.e., 4 weeks after GNX. Thus, Tac1/Tac2KO mice showed a decreased frequency of LH pulses (that reached statistical significance in females) and a decreased amplitude in males determined by the AUC of the total secretory $\mathrm{LH}$ mass (Fig. 3a-f).

Despite significant alteration in the overall pattern of $\mathrm{LH}$ release, the expression of the genes involved in the shaping of kisspeptin pulses, i.e., Kiss 1, Pdyn, and the tachykinin receptors Tacr1, Tacr2, and Tac3r, was similar between both groups in the $\mathrm{MBH}$ (online suppl. Fig. 1; see www.karger.com/doi/10.1159/000509222 for all online suppl. material).

\section{Tachykinin Signaling Is Necessary for the Preovulatory LH Surge}

The lower number of CL in females suggested that the infertile phenotype of $80 \%$ of the Tac1/Tac2KO females 

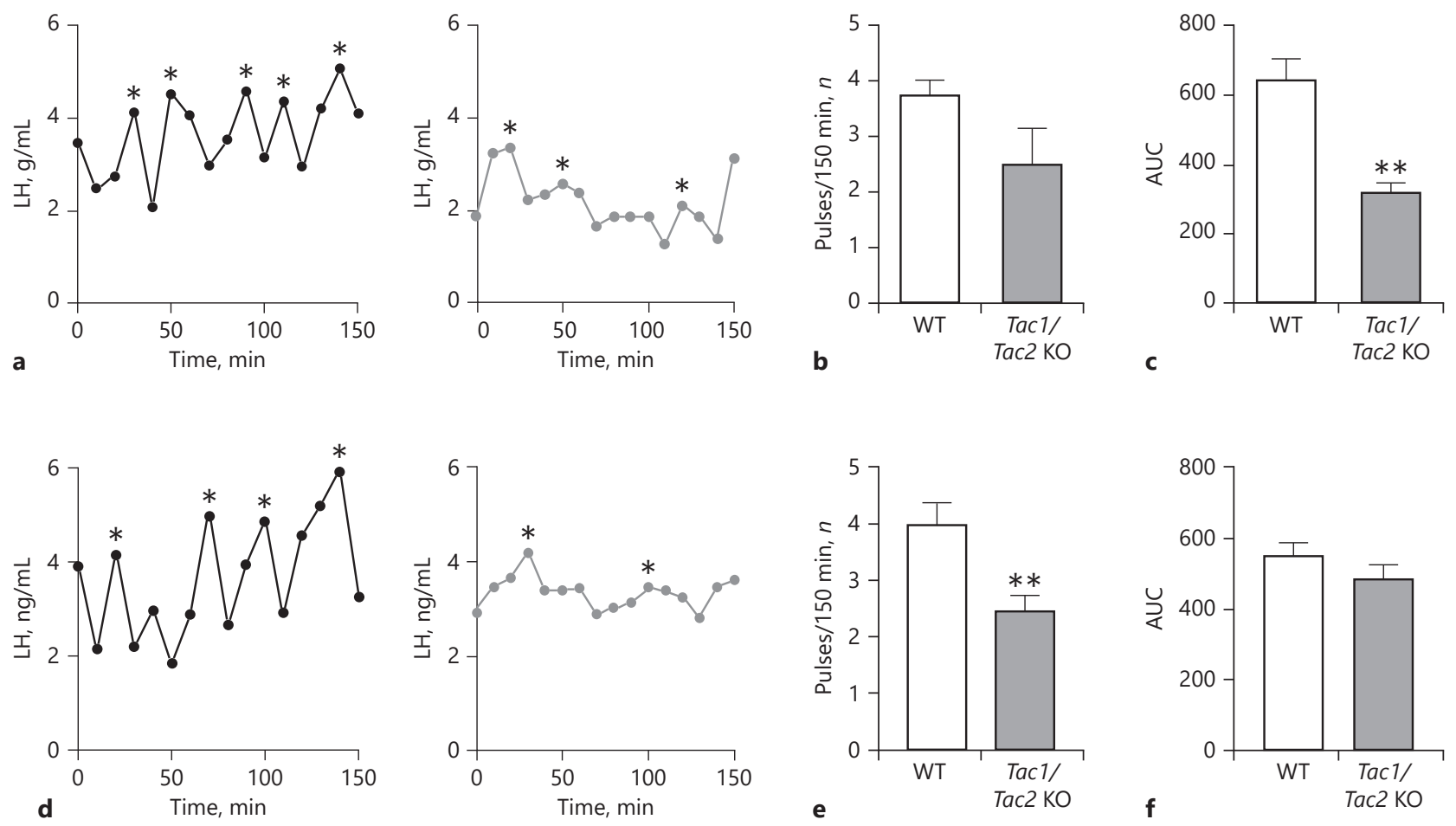

Fig. 3. Pattern of LH pulsatility in gonadectomized WT and Tac1/Tac2KO mice. LH samples were collected every $10 \mathrm{~min}$ for $150 \mathrm{~min}$ in males and females 4 weeks after GNX. The pattern of LH pulses, the number of pulses/150 min, and the total secretory mass assessed by the AUC in males ( $n \geq 3$ /group; a-c) and females ( $n \geq 6$ /group; d-f) are shown. ${ }^{* *} p<0.01$. Student $t$ test. ${ }^{*}$ LH pulses following the protocol described in Materials and Methods.

was due to an ovulatory deficit. In order to evaluate the role of tachykinins on the positive feedback of sex steroids required for ovulation, WT, Tac1KO, Tac2KO, and Tac1/ Tac2KO female mice were subjected to an $\mathrm{LH}$ surge-inducing protocol and blood was collected in the morning $(\sim 10$ : 00 a.m.) and evening, after lights off ( 7:00 p.m.). KO mice for a single Tac gene (i.e., Tac1 or Tac2) displayed a discernible LH surge, which was not statistically different from controls. However, Tac1/Tac2KO mice failed to display an LH surge (Fig. 4a). This finding suggests that the single Tac KO models develop a compensatory mechanism likely driven by the remaining (intact) tachykinin system. In order to test whether this compensation is acquired throughout development in the chronic absence of a tachykinin system or it is already present in WT mice, we subjected a new cohort of WT females to the same LH surge protocol used in $\mathrm{KO}$ mice. In this case, mice were also injected i.p. with specific antagonists of NK1R or NK3R in the morning (10:00 a.m.) and afternoon (5:00 p.m.). Both antagonists individually were able to block the LH surge (Fig. 4b).

\section{Discussion}

The role of tachykinins in regulating reproductive function has been described in several species. Tachykinins (NKA, NKB, and SP) have been shown to significantly stimulate gonadotropin release (in a sex steroiddependent manner in the case of NKA and NKB) $[1,27]$. The present study extends our knowledge of the role of tachykinins in puberty onset, generation of $\mathrm{GnRH}$ pulses, and mounting of the preovulatory LH surge.

\section{Tachykinins Are Required for the Proper Timing of}

Puberty Onset

Overall, the action of tachykinins on the HPG axis has been documented from early developmental stages, where NKB has been posed with the critical role of serving as a stimulator of kisspeptin release to awaken the reproductive axis, therefore kick-starting puberty onset [1, $27,28]$. Studies using a single deficiency of tachykinin models ( Tac1KO and Tac2KO) have exhibited a delay in 


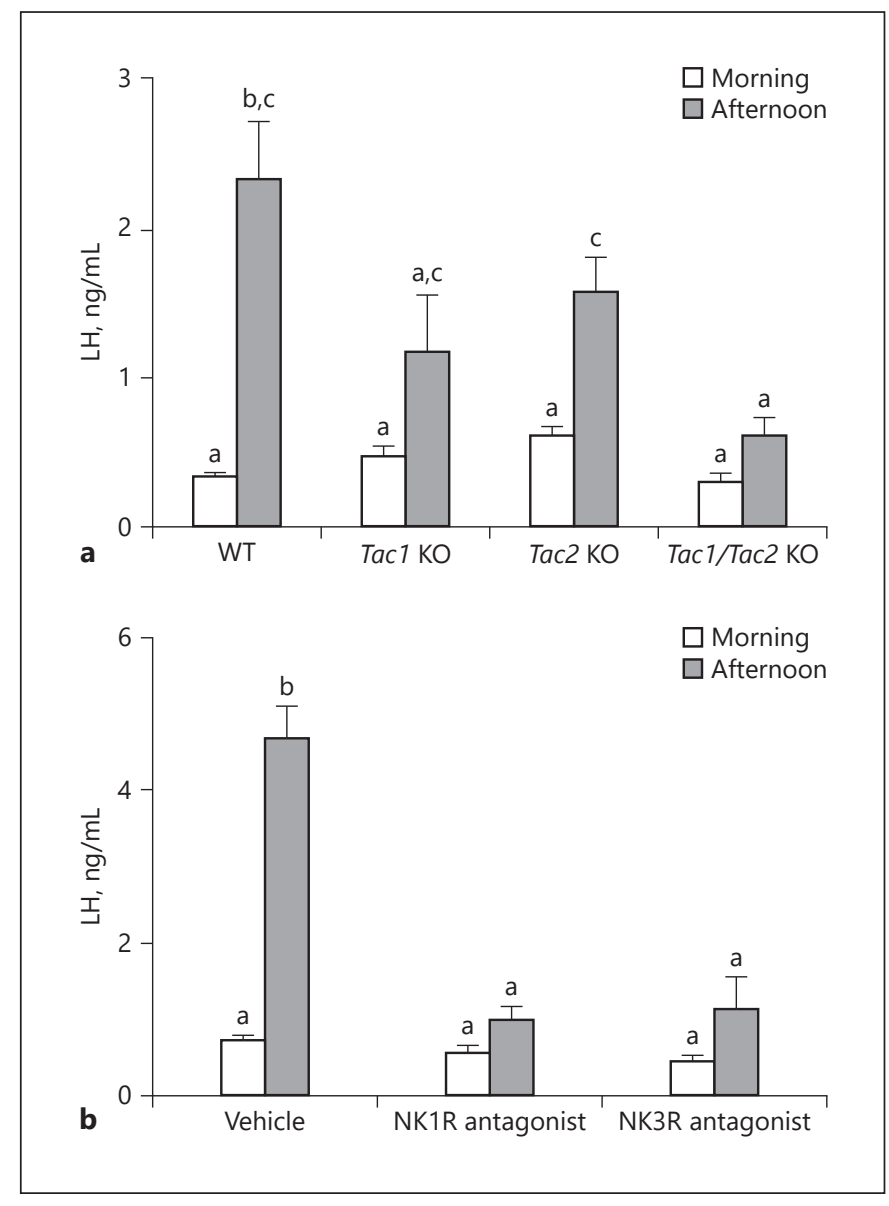

Fig. 4. Preovulatory $\mathrm{LH}$ surge in Tac1KO, Tac2KO and Tac1/ Tac2KO, and WT after NK1R and NK3R blockade. Circulating LH measurements in the morning (10:00 a.m.) and afternoon (7:00 p.m.) after an LH surge-inducing protocol in WT, Tac1KO, Tac2KO, and Tac1/Tac2KO mice (a; $n=5 /$ group) and in WT mice after the administration of NK1R or NK3R antagonists ( $\mathbf{b} ; n=5$ / group). Different letters indicate significantly different values after a repeated measures two-way ANOVA and a Fisher post hoc test.

puberty onset in males and females, supporting that not only NKB but also NKA/SP have a role in the timing of the pubertal release of kisspeptin/GnRH. However, all Tac1KO and Tac2KO mice eventually displayed signs of sexual maturation (PS in males and $\mathrm{VO}+$ first estrus in females) [11, 17-19]. Of note, these studies describing the phenotype of the single KO models were performed in our facility under the same conditions as the present studies in Tac1/Tac2KO mice. Interestingly, while Tac1/ Tac2KO male mice resembled the phenotype of Tac1KO mice (i.e., 4- to 5-day delay in PS) [19], female Tac1/ Tac2KO mice presented a normal time of $\mathrm{VO}$ but an absence of the first estrus, unlike the single KO models [11,
17]. The reason for this discrepancy in the timing of $\mathrm{VO}$ is unclear and suggests the existence of sufficient circulating levels of estradiol (E2) to induce the normal progression of this pubertal marker. Nonetheless, while VO is a direct measure of circulating E2 levels, the absence of a detectable first estrus for 45 days following $\mathrm{VO}$ in the double $\mathrm{KO}$ females denotes a central impairment in the normal ovulatory process. This impairment is more severe than in single $\mathrm{KO}$ mouse models, which display a detectable first estrus shortly after VO [11, 17].

Furthermore, the impairment to achieve estrus in Tac1/Tac $2 \mathrm{KO}$ female mice is maintained throughout the life of the mouse (at 3 and 8 months), with only sporadic estrus observed in some females ( $<2$ estrous phases in 30 days). This phenotype is in direct contrast to that of Tac1KO females, which display regular estrous cycles [11], and Tac2KO females, which transition from irregular cycles at 3 months to regular ones at 8 months [17].

\section{Tachykinins Are Essential for the Generation of the Preovulatory LH Surge}

The sporadic estrus observed in some Tac1/Tac2KO females is in line with the $20 \%$ of pregnancies observed in these mice, in striking contrast to the $100 \%$ success rate of pregnancies in the single KO models. Of note, despite their fertile phenotype, single Tac1 and Tac2 KO models present smaller ovaries and fewer CL that led to smaller litters in Tac1KO but not in Tac2KO [11, 17]. However, in the fraction of Tac1/Tac2KO mice that got pregnant, the litter size was even smaller than in Tac1KO females and the pregnancy latency was larger than in both single KO models, highlighting the more severe reproductive impairment in the complete absence of tachykinin signaling. This phenotype in Tac1/Tac2KO female mice strongly suggested a failure to mount a proper preovulatory LH surge. Because ovulation has not been studied in previous experiments characterizing the single tachykinin KO models, we set out to compare the ability of each model to display an LH surge compared to WT littermate controls. Interestingly, Tac1KO and Tac2KO mice presented a trend toward smaller increases in $\mathrm{LH}$ release (LH surge) than in controls. This effect is in line with the lower number of CL described for each model although the amount of $\mathrm{LH}$ released was sufficient to attain successful pregnancies in all of the animals of each group $[11,17]$. Not surprisingly, given the severe decrease in the fertility rate among Tac1/Tac2KO females, we did not observe an LH surge in any of the animals tested. This defect suggests that the products of both tachykinin genes are required for full ovulatory capabili- 
ties in females. The absence of one of the tachykinin systems reduces the magnitude of the $\mathrm{LH}$ surge, in accordance with the decreased fertility rate of single $\mathrm{KO}$ females [11, 17]; however, the complete blunting of the LH surge in the absence of both tachykinin systems leads to complete infertility in $80 \%$ of females. This is in line with the reversal phenotype of the hypogonadal state described in patients with NKB signaling deficiency, which has been speculated to be mediated by NKA/SP. Nonetheless, NKA/SP deficiency in patients (TAC1/TACR1/ TACR2 mutants) has not been associated with hypogonadism or fertility impairments, despite the documented stimulatory effect of SP on LH release in humans [29]. Thus, we can infer that the absence of TAC1 (SP/NKA) signaling in humans induces a milder effect on fertility than the absence of TAC3 (NKB), resembling the fertile phenotype of Tac1-deficient mice.

Nonetheless, the decrease in the fertility rate of double KO females contrasts with the fact that $75 \%$ of the ovaries of these females showed at least $1 \mathrm{CL}$. While this explains the reduction of the number of pups per litter, it does not explain the $80 \%$ infertility rate. To interpret these data, it is important to put in context the potential extent of the contribution of the tachykinin systems to reproduction, which might involve a role in sexual behavior. We recently identified a population of NK3R expressing neurons in the medial amygdala (MeA) of the mouse that can significantly stimulate $\mathrm{LH}$ release [30]. Because the amygdala is critical for sexual behavior [31-34], it is plausible that Tac1/Tac2KO females present a behavioral deficit, such as lordosis impairments, that further contributes to the infertile phenotype despite the presence of sporadic ovulation (i.e. CL).

Of note, the existence of CL in mice with a reduced magnitude of their preovulatory LH surge is consistent with previous reports in mice [35], which suggests that the required magnitude of an $\mathrm{LH}$ surge to induce ovulation is substantially lower than what is normally achieved in a WT mouse. This lower requirement of the magnitude of the LH surge might account for the sporadic ovulation observed in some Tac1/Tac2KO females.

We further investigated this novel role of tachykinins in the induction of the LH surge by assessing the effect of acutely blocking the NKB or SP receptor (NK3R and NK1R, respectively) in adult WT females subjected to a similar LH surge-inducing protocol as was previously carried out in the KO models. Surprisingly, both antagonists alone were able to suppress the LH surge when injected in the morning and afternoon of the day of the expected LH surge, further highlighting that both tachyki- nin systems have an active role in triggering ovulation. This effect is in line with previous reports in humans and monkeys, indicating that NK1R and NK3R antagonists delay the LH surge $[36,37]$. Moreover, the NK3R agonist senktide induces an LH surge in ewes during the follicular phase when injected into the retrochiasmatic and POA $[38,39]$. Our current data in mice document a previously unknown but critical role of tachykinins in ovulation and, furthermore, demonstrate that compensation of the congenital absence of one of these tachykinin systems can develop in mice, likely as an evolutionary fail-safe mechanism to maintain reproductive function.

Furthermore, the lack of an LH surge after acute blockade of one of the tachykinin receptors suggests that there is no duplication in their role that could lead to an additive effect - as could be inferred by the decrease in the magnitude of the LH surge by approximately half of the normal magnitude observed in each individual $\mathrm{KO}$ model. This experiment supports the contention that there is, indeed, an acquired capacity to ovulate in congenitally deficient single tachykinin deficient models. Whether this compensation is achieved by the additional tachykinin system taking over, for example, SP/NK1R in the absence of NKB signaling or through cross-activation of the different ligand/receptors, such as SP acting on NK3R, is yet unknown. In any case, this effect might occur directly at the level of Kiss1 neurons in the AVPV/PeN (Kiss $1^{\mathrm{AVPV} / \mathrm{PeN}}$, which are responsible for mounting the LH surge by releasing a surge of kisspeptin in response to rising E2 levels) and/or GnRH neurons since both populations of neurons express NK1R and NK3R in similar percentages (25 and $10 \%$, respectively) [6].

\section{GnRH Pulses Can Occur in the Absence of Tachykinin} Signaling

In addition to the novel role in induction of the $\mathrm{LH}$ surge discussed above, tachykinins have been posed as components of the GnRH pulse generator, especially the $\mathrm{NKB} / \mathrm{NK} 3 \mathrm{R}$ system, by stimulating the pulsatile release of kisspeptin from Kiss $1^{\mathrm{ARC}}$ neurons. However, we recently demonstrated in mice that, in the absence of NKB signaling (Tac2KO), LH pulses are still present albeit at a slower frequency and smaller amplitude, in line with NKB signaling-deficient patients [40, 41]. Importantly, this alteration in LH pulsatility did not affect fertility in mice and was sufficient to reverse infertility in human mutants, suggesting that successful reproduction can be achieved with a minimal baseline of $\mathrm{LH}$ pulses.

Interestingly, the concept of the role of NKB (in coordination with dynorphin) as the source of the LH pulses 
Fig. 5. Schematic representation of the pattern of pulsatile and surge LH release. Kiss1 neurons present intrinsic activity that leads to a basal level of tonic release of $\mathrm{LH}$ that is sufficient to maintain reproduction in males. In the presence of tachykinins, $\mathrm{LH}$ pulses acquire a normal frequency and amplitude (red). In females, tachykinins are required for the formation of the preovulatory LH surge (red). Whether the action of SP/NKA and NKB is direct on Kiss $1^{\mathrm{AVPV} / \mathrm{PeN}}$ neurons or through intermediate neurons, as well as the neuronal population that is the source of these tachykinins, remains to be deciphered.

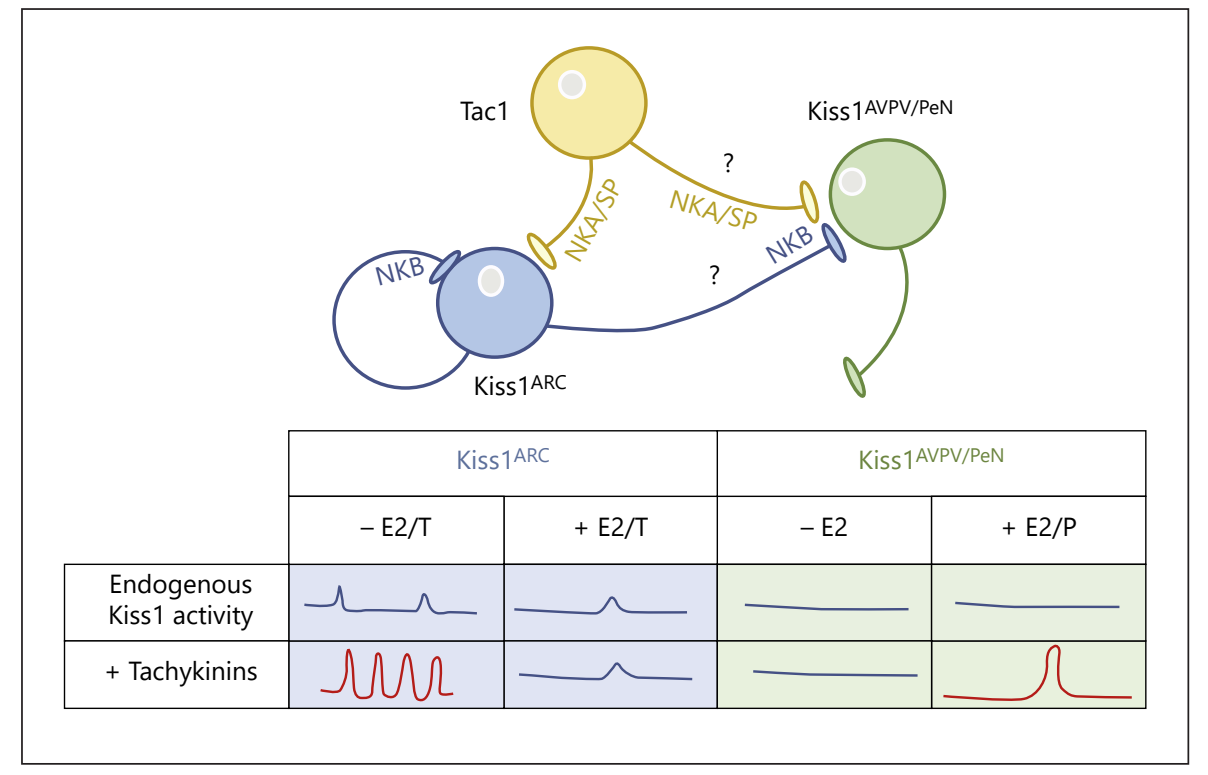

is challenged by studies showing that continuous kisspeptin infusion in NKB signaling-deficient patients, as well as in a sheep model of pharmacological antagonism of NK3R [42], leads to an increase in LH pulsatility - suggesting that Kiss $1^{\text {ARC }}$ neurons are not the GnRH pulse generator or that additional pulse generators exist or develop. However, this effect (i.e., induction of LH pulses after kisspeptin administration) is not observed in Tac2KO mice, which only respond with a sustained increase in circulating LH levels after kisspeptin treatment [40]. While species differences might exist, important questions remain to fully reconcile these data in different species and thus understand the whole mechanism underlying $\mathrm{GnRH}$ pulses. For instance, the data in humans and sheep suggest the existence of a pulsatile inhibitory factor that must act on $\mathrm{GnRH}$ neurons to cease every pulse of $\mathrm{GnRH}$ after kisspeptin stimulation. Otherwise, each pulse of kisspeptin would depolarize GnRH neurons for up to $30 \mathrm{~min}$ [43] (or longer after continuous kisspeptin administration), while it is known that LH pulses occur as frequently as every $<10 \mathrm{~min}$ [44] in gonadectomized mice. This pulsatile inhibition upon GnRH neurons might be mediated by dynorphin based on studies in sheep [45].

Initial hypotheses for the presence of rudimentary $\mathrm{LH}$ pulses in NKB-deficient mice and humans included compensation by NKA/SP. Our current data in complete tachykinin-deficient mice (i.e., Tac1/Tac2KO mice) debunks this hypothesis. We demonstrate that LH pulsatility is preserved in the complete absence of tachykinins, albeit at a lower frequency, resembling the profile of

Tachykinin Signaling Is Required for $\mathrm{LH}$

Surge and Normal LH Pulses
Tac2KO mice [40]. This phenotype indicates that the source of these rudimentary LH pulses is not the compensation by other tachykinins. As in Tac2KO mice, basal LH pulses in Tac1/Tac2KO mice are able to maintain a tonic release of LH that is sufficient to stimulate the synthesis and release of sex steroids to achieve sexual maturation (PS and VO, although with a certain delay compared to controls). These basal LH pulses are therefore enough to activate the HPG axis, as evidenced by the normal fertility and testicular histology in Tac1/Tac2KO males. In females, this low stimulation of the ovary might be sufficient to induce gametogenesis and some estradiol production that might be insufficient for normal gonadal development, leading to smaller ovaries and large periods in diestrus, in addition to the ovulatory impairments described above.

Nonetheless, the presence of circulating sex steroids in male and female double $\mathrm{KO}$ mice is further evidenced by the absence of changes in the expression of the genes encoding the known ligands and the receptors controlling kisspeptin release in Kiss $1^{\mathrm{ARC}}$ neurons (Kiss1, Pdyn, Tacr1, and Tacr3). The expression of these genes is highly regulated (inhibited) by circulating sex steroids $[5,6]$. Therefore, the lack of change observed in the expression of these genes indicates that there is a sufficient sex steroid level circulating in the animal to hold their expression down to control levels.

Moreover, this study in Tac1/Tac2KO uncovered an important sex difference in the mechanism/s underlying the generation of $\mathrm{GnRH} / \mathrm{LH}$ pulses as observed by the sig- 
nificantly lower amplitude of LH pulses in male (but not female) gonadectomized Tac1/Tac2KO mice compared to controls. This difference might indicate the existence of sexual dimorphism in the mechanisms underlying $\mathrm{GnRH}$ pulses that remains to be further characterized.

The main question arising from the present data is: what drives these rudimentary LH pulses? These pulses could be explained by the existence of yet another pulse generator upstream of Kiss ${ }^{\text {ARC }}$ neurons or, a more likely explanation, the pacemaker activity of Kiss $1^{\text {ARC }}$ neurons, which has been already demonstrated [46]. In this context, tachykinins would act as modulators of the activity of the pacemaker. Along these lines, our data demonstrated a delay in the LH response to the removal of the negative feedback of sex steroids in both sexes. While LH was significantly elevated 2 days after GNX in WT mice, LH levels in $\mathrm{KO}$ mice of both sexes remained unchanged at this time (with LH levels reaching that of WT mice by 7 days postsurgery). This delay suggests a role for tachykinins as accelerators of kisspeptin pulsatility to adapt to changing levels of sex steroids. Then, upon removal of sex steroids, tachykinins in WT mice would rapidly increase the frequency and amplitude of kisspeptin pulses in an attempt to achieve a rapid return to normal sex steroid levels (Fig. 5). The same mechanism would apply in regulation of the timing of puberty onset. Thus, in the absence of tachykinins (i.e., the accelerator of the endogenous pacemaker activity), puberty onset would take longer, as we have observed in tachykinin-deficient models. This action of tachykinins might occur directly on Kiss ${ }^{\text {ARC }}$ neurons, which express NK1R and NK3R (50 and $>90 \%$, respectively) [6] and have been shown to directly respond to SP and NKA in addition to NKB [47].

Overall, our findings confirmed a role for tachykinins in the proper timing of puberty onset and fine tuning of pulsatile LH release to circulating sex steroids. However, these data evidence that tachykinins are not necessary for
LH pulses, which remain present at a lower, basal rate in their absence, being sufficient to achieve puberty onset and fertility in male mice. Finally, we showed for the first time that NK1R and NK3R signaling are necessary for the formation of the preovulatory LH surge in females. However, in the congenital absence of one of these systems, compensation from the other one takes place in order to preserve fertility. This role of tachykinins in ovulation raises novel possibilities for the use of agonists and antagonists of tachykinin receptors in fertility induction protocols and as novel nonsteroidal contraceptive approaches.

\section{Statement of Ethics}

All animal studies were approved by the Brigham and Women's Hospital Institutional Animal Care and Use Committee.

\section{Conflict of Interest Statement}

The authors have nothing to disclose.

\section{Funding Sources}

This work was supported by grants R01HD090151 and R21HD095383 from the Eunice Kennedy Shriver National Institute of Child Health and Human Development (NICHD) and National Institute of Health (NIH) to V.M.N. and by the International Brain Research Organization (IBRO) Fellowship and the Lalor Foundation Research Fellowship to R.T.

\section{Author Contributions}

S.L. and V.M.N. designed the experiments; S.L., C.F., R.T., C.A.M., and A.G. performed the experiments; S.B.S. provided essential material; S.L., C.F., and V.M.N. discussed the data and wrote this paper.

\section{References}

1 Fergani C, Navarro VM. Expanding the Role of Tachykinins in the Neuroendocrine Control of Reproduction. Reproduction. 2016 Nov;153(1):R1-14

2 Topaloglu AK, Reimann F, Guclu M, Yalin AS, Kotan LD, Porter KM, et al. TAC3 and TACR3 mutations in familial hypogonadotropic hypogonadism reveal a key role for Neurokinin B in the central control of reproduction. Nat Genet. 2009 Mar;41(3):354-8.
3 Young J, Bouligand J, Francou B, Raffin-Sanson ML, Gaillez S, Jeanpierre M, et al. TAC3 and TACR3 defects cause hypothalamic congenital hypogonadotropic hypogonadism in humans. J Clin Endocrinol Metab. 2010 May; 95(5):2287-95.

4 Goodman RL, Lehman MN, Smith JT, Coolen LM, de Oliveira CV, Jafarzadehshirazi MR, et al. Kisspeptin neurons in the arcuate nucleus of the ewe express both dynorphin A and neurokinin B. Endocrinology. 2007 Dec;148(12): 5752-60.
5 Navarro VM, Gottsch ML, Chavkin C, Okamura H, Clifton DK, Steiner RA. Regulation of gonadotropin-releasing hormone secretion by kisspeptin/dynorphin/neurokinin B neurons in the arcuate nucleus of the mouse. J Neurosci. 2009 Sep;29(38):11859-66.

6 Navarro VM, Bosch MA, León S, Simavli S, True C, Pinilla L, et al. The integrated hypothalamic tachykinin-kisspeptin system as a central coordinator for reproduction. Endocrinology. 2015 Feb;156(2):627-37. 
7 Hidalgo-Díaz C, Castaño JP, López-Pedrera R, Malagón MM, García-Navarro S, GraciaNavarro F. A modulatory role for substance $P$ on the regulation of luteinizing hormone secretion by cultured porcine gonadotrophs. Biol Reprod. 1998 Mar;58(3):678-85.

8 Ohtsuka S, Miyake A, Nishizaki T, Tasaka K, Aono T, Tanizawa O. Substance P stimulates gonadotropin-releasing hormone release from rat hypothalamus in vitro with involvement of oestrogen. Acta Endocrinol (Copenh). 1987 Jun;115(2):247-52.

9 Ruiz-Pino F, Garcia-Galiano D, ManfrediLozano M, Leon S, Sánchez-Garrido MA, Roa $\mathrm{J}$, et al. Effects and interactions of tachykinins and dynorphin on FSH and LH secretion in developing and adult rats. Endocrinology. 2015 Feb;156(2):576-88.

10 Shamgochian MD, Leeman SE. Substance P stimulates luteinizing hormone secretion from anterior pituitary cells in culture. Endocrinology. 1992 Aug;131(2):871-5.

11 Simavli S, Thompson IR, Maguire CA, Gill JC, Carroll RS, Wolfe A, et al. Substance p regulates puberty onset and fertility in the female mouse. Endocrinology. 2015 Jun; 156(6): 2313-22.

12 Traczyk WZ, Pau KY, Kaynard AH, Spies HG. Modulatory role of substance $\mathrm{P}$ on gonadotropin and prolactin secretion in the rabbit. J Physiol Pharmacol. 1992 Sep;43(3):279-97.

13 Tsuruo Y, Kawano H, Hisano S, Kagotani Y, Daikoku S, Zhang T, et al. Substance P-containing neurons innervating LHRH-containing neurons in the septo-preoptic area of rats. Neuroendocrinology. 1991 Mar;53(3):23645.

14 Sahu A, Kalra SP. Effects of tachykinins on luteinizing hormone release in female rats: potent inhibitory action of neuropeptide $\mathrm{K}$. Endocrinology. 1992 Mar;130(3):1571-7.

15 León S, Fergani C, Talbi R, Simavli S, Maguire CA, Gerutshang A, et al. Characterization of the Role of NKA in the Control of Puberty Onset and Gonadotropin Release in the Female Mouse. Endocrinology. 2019 Oct; 160(10):2453-63.

16 Gianetti E, Tusset C, Noel SD, Au MG, Dwyer AA, Hughes VA, et al. TAC3/TACR3 mutations reveal preferential activation of gonadotropin-releasing hormone release by neuroki$\operatorname{nin} \mathrm{B}$ in neonatal life followed by reversal in adulthood. J Clin Endocrinol Metab. 2010 Jun;95(6):2857-67.

17 True C, Nasrin Alam S, Cox K, Chan YM, Seminara SB. Neurokinin B is critical for normal timing of sexual maturation but dispensable for adult reproductive function in female mice. Endocrinology. 2015 Apr;156(4):138697.

18 Yang JJ, Caligioni CS, Chan YM, Seminara $\mathrm{SB}$. Uncovering novel reproductive defects in neurokinin $B$ receptor null mice: closing the gap between mice and men. Endocrinology. 2012 Mar;153(3):1498-508.
19 Maguire CA, Song YB, Wu M, León S, Carroll RS, Alreja M, et al. Tac1 Signaling Is Required for Sexual Maturation and Responsiveness of GnRH Neurons to Kisspeptin in the Male Mouse. Endocrinology. 2017 Jul;158(7): 2319-29.

20 Parnet P, Mitsuhashi M, Turck CW, Kerdelhue B, Payan DG. Tachykinin receptor crosstalk. Immunological cross-reactivity between the external domains of the substance $\mathrm{K}$ and substance P receptors. Brain Behav Immun. 1991 Mar;5(1):73-83.

21 Steinhoff MS, von Mentzer B, Geppetti P, Pothoulakis C, Bunnett NW. Tachykinins and their receptors: contributions to physiological control and the mechanisms of disease. Physiol Rev. 2014 Jan;94(1):265-301.

22 Navarro VM, Ruiz-Pino F, Sánchez-Garrido MA, García-Galiano D, Hobbs SJ, ManfrediLozano M, et al. Role of neurokinin B in the control of female puberty and its modulation by metabolic status. J Neurosci. 2012 Feb; 32(7):2388-97.

23 León S, Barroso A, Vázquez MJ, GarcíaGaliano D, Manfredi-Lozano M, Ruiz-Pino F, et al. Direct Actions of Kisspeptins on GnRH Neurons Permit Attainment of Fertility but are Insufficient to Fully Preserve Gonadotropic Axis Activity. Sci Rep. 2016 Jan;6(1): 19206.

24 Martin C, Navarro VM, Simavli S, Vong L, Carroll RS, Lowell BB, et al. Leptin-responsive GABAergic neurons regulate fertility through pathways that result in reduced kisspeptinergic tone. J Neurosci. 2014 Apr;34(17):604756.

25 Steyn FJ, Wan Y, Clarkson J, Veldhuis JD, Herbison AE, Chen C. Development of a methodology for and assessment of pulsatile luteinizing hormone secretion in juvenile and adult male mice. Endocrinology. 2013 Dec; 154(12):4939-45

26 Czieselsky K, Prescott M, Porteous R, Campos P, Clarkson J, Steyn FJ, et al. Pulse and Surge Profiles of Luteinizing Hormone Secretion in the Mouse. Endocrinology. 2016 Dec; 157(12):4794-802.

27 Leon S, Navarro VM. Novel Biology of Tachykinins in Gonadotropin-Releasing Hormone Secretion. Semin Reprod Med. 2019 May; 37(3):109-18

28 Gill JC, Navarro VM, Kwong C, Noel SD, Martin C, Xu S, et al. Increased neurokinin B (Tac2) expression in the mouse arcuate nucleus is an early marker of pubertal onset with differential sensitivity to sex steroid-negative feedback than Kiss1. Endocrinology. 2012 Oct;153(10):4883-93.

29 Coiro V, Volpi R, Capretti L, Caiazza A, Marcato A, Bocchi R, et al. Luteinizing hormone response to an intravenous infusion of substance P in normal men. Metabolism. 1992 Jul;41(7):689-91.
30 Fergani C, Leon S, Padilla SL, Verstegen AM, Palmiter RD, Navarro VM. NKB signaling in the posterodorsal medial amygdala stimulates gonadotropin release in a kisspeptin-independent manner in female mice. eLife. 2018 Dec;7:7.

31 Holder MK, Mong JA. The Role of Ovarian Hormones and the Medial Amygdala in Sexual Motivation. Curr Sex Health Rep. 2017 Dec;9(4):262-70.

32 Kondo Y. Lesions of the medial amygdala produce severe impairment of copulatory behavior in sexually inexperienced male rats. Physiol Behav. 1992 May;51(5):939-43.

33 Kondo Y, Sakuma Y. The medial amygdala controls the coital access of female rats: a possible involvement of emotional responsiveness. Jpn J Physiol. 2005 Dec;55(6):34553.

34 Rajendren G, Moss RL. The role of the medial nucleus of amygdala in the mating-induced enhancement of lordosis in female rats: the interaction with luteinizing hormone-releasing hormone neuronal system. Brain Res. 1993 Jul;617(1):81-6.

35 Toufaily C, Schang G, Zhou X, Wartenberg P, Boehm U, Lydon JP, et al. Impaired LH surge amplitude in gonadotrope-specific progesterone receptor knockout mice. J Endocrinol. 2020 Jan;244(1):111-22.

36 Kerdelhué B, Williams RF, Lenoir V, Fardin $\mathrm{V}$, Kolm P, Hodgen GD, et al. Variations in plasma levels of substance $P$ and effects of a specific substance $P$ antagonist of the $\mathrm{NK}(1)$ receptor on preovulatory $\mathrm{LH}$ and $\mathrm{FSH}$ surges and progesterone secretion in the cycling cynomolgus monkey. Neuroendocrinology. 2000 Apr;71(4):228-36.

37 Skorupskaite K, George JT, Veldhuis JD, Anderson RA. Neurokinin B Regulates Gonadotropin Secretion, Ovarian Follicle Growth, and the Timing of Ovulation in Healthy Women. J Clin Endocrinol Metab. 2018 Jan; 103(1):95-104.

38 Billings HJ, Connors JM, Altman SN, Hileman SM, Holaskova I, Lehman MN, et al. Neurokinin B acts via the neurokinin-3 receptor in the retrochiasmatic area to stimulate luteinizing hormone secretion in sheep. Endocrinology. 2010 Aug;151(8):3836-46.

39 Porter KL, Hileman SM, Hardy SL, Nestor CC, Lehman MN, Goodman RL. Neurokinin-3 receptor activation in the retrochiasmatic area is essential for the full pre-ovulatory luteinising hormone surge in ewes. J Neuroendocrinol. 2014 Nov;26(11):77684.

40 Lippincott MF, León S, Chan YM, Fergani C, Talbi R, Farooqi IS, et al. Hypothalamic Reproductive Endocrine Pulse Generator Activity Independent of Neurokinin B and Dynorphin Signaling. J Clin Endocrinol Metab. 2019 Oct;104(10):4304-18. 
41 Young J, George JT, Tello JA, Francou B, Bouligand J, Guiochon-Mantel A, et al. Kisspeptin restores pulsatile $\mathrm{LH}$ secretion in patients with neurokinin B signaling deficiencies: physiological, pathophysiological and therapeutic implications. Neuroendocrinology. 2013;97(2):193-202.

42 Clarke IJ, Li Q, Henry BA, Millar RP. Continuous Kisspeptin Restores Luteinizing Hormone Pulsatility Following Cessation by a Neurokinin B Antagonist in Female Sheep. Endocrinology. 2018 Feb;159(2):639-46.
43 Zhang C, Roepke TA, Kelly MJ, Rønnekleiv OK. Kisspeptin depolarizes gonadotropin-releasing hormone neurons through activation of TRPC-like cationic channels. J Neurosci. 2008 Apr;28(17):4423-34.

44 Han SY, Cheong I, McLennan T, Herbison AE. Neural Determinants of Pulsatile Luteinizing Hormone Secretion in Male Mice. Endocrinology. 2020 Feb;161(2):bqz045.

45 Weems PW, Coolen LM, Hileman SM, Hardy S, McCosh RB, Goodman RL, et al. Evidence That Dynorphin Acts Upon KNDy and GnRH Neurons During GnRH Pulse Termination in the Ewe. Endocrinology. 2018 Sep; 159(9):3187-99.
46 Gottsch ML, Popa SM, Lawhorn JK, Qiu J, Tonsfeldt KJ, Bosch MA, et al. Molecular properties of Kiss1 neurons in the arcuate nucleus of the mouse. Endocrinology. $2011 \mathrm{Nov}$; 152(11):4298-309.

47 de Croft S, Boehm U, Herbison AE. Neurokinin $B$ activates arcuate kisspeptin neurons through multiple tachykinin receptors in the male mouse. Endocrinology. 2013 Aug; 154(8):2750-60. 